\title{
Giant lipoma of the thigh: A case report
}

\author{
A. Righi*, O. Pantalone, G. Tagliaferri
}

Department of Radiology, San Paolo Hospital, Civitavecchia, Roma, Italy

\section{KEYWORDS \\ Lipoma; \\ Ultrasonography; \\ CT.}

\section{Introduction}

A lipoma is a very common mesenchymal tumor which can occur in any part of the body where there are fat cells,

\footnotetext{
* Corresponding author. Via Mattia Battistini 209, 00167 Roma, Italy.

E-mail address: alessandrorighi@gmail.com (A. Righi).
}

\begin{abstract}
A lipoma is a benign tumor which can occur in any part of the body; it is very frequent and can reach a considerable size. Differentiation between lipoma and liposarcoma of low grade malignancy represents an important diagnostic problem, and valuable help in the differential diagnosis is provided by ultrasonography (US), computed tomography (CT), magnetic resonance imaging (MRI), biopsy and/or modern immunohistochemistry. The authors report the case of a 50-year-old man who was referred to their department due to the presence of a large mass growing on the upper thigh of the right leg; over 7 years it had steadily increased in size causing pain and functional impotence. US of the soft tissues and CT scanning were performed. Densitometric values of the mass suggested adipose tissue, which was subsequently confirmed by biopsy.
\end{abstract}

Sommario I lipomi sono tumori benigni molto frequenti che si localizzano a tutti i livelli e possono raggiungere dimensioni ragguardevoli. Esiste un problema diagnostico importante nella differenziazione tra lipoma e liposarcoma a basso grado di malignità e un valido supporto nella diagnostica differenziale è fornito dall'ecografia, dalla TC, dalla Risonanza Magnetica, dall'esame bioptico e dai moderni metodi immunoistochimici. Riportiamo il caso di un uomo di 50 anni che giunge alla nostra osservazione per la presenza di una grossolana massa a livello della radice della coscia di destra e progressivamente aumentata di dimensioni con relativo dolore ed impotenza funzionale. Vengono eseguiti un'ecografia dei tessuti molli ed un successivo esame TC. La massa mostrava valori densitometrici di tipo adiposo come poi verrà successivamente confermato dall'esame bioptico.

(c) 2012 Elsevier Srl. All rights reserved. particularly in the subcutaneous adipose tissue. It is a single or multiple benign tumor consisting of fat globules; it is soft and of a rounded shape and can reach a considerable size [1]. The volume tends to increase with the increase in body weight, but it does not regress as a consequence of weight loss.

Differentiation between lipoma and liposarcoma of low grade malignancy represents an important diagnostic problem [2] as these lesions require different types of therapeutic management. Valuable help in the differential 
diagnosis is provided by computed tomography (CT), magnetic resonance imaging (MRI), biopsy and/or modern immunohistochemistry $[3,6]$. The authors report the case of a giant lipoma measuring approximately $35 \mathrm{~cm}$ in diameter growing on the upper thigh of the right leg.

\section{Case report}

The authors report the case of a 50-year-old man who was referred to their department due to the presence of a large mass which had occurred on the upper thigh of the right leg about 7 years earlier; it had steadily increased in size. The patient reported pain, functional impairment and edema of the superficial tissues. Ultrasonography (US) was performed and integrated with CT. US carried out using a highfrequency surface probe showed a large mass of markedly inhomogeneous echotexture associated with reactive skin thickening of $18 \mathrm{~mm}$ (epidermis and dermis) in the more distal part of the swelling due to the presence of edema. The edematous portion near the mass appeared as linear anechoic areas in a context of a hyperechoic structure and reactive skin thickening which in the peripheral portion reached about $18 \mathrm{~mm}$ [Fig. 1]. Color Doppler US did not reveal vascularity within the lesion. Diagnostic investigation was completed with multislice CT (Toshiba Aquilion 8slice) which confirmed the presence of a $10 \mathrm{~cm}$ thick mass of $35 \mathrm{~cm}$ in craniocaudal diameter extending inferiorly as an exophytic growth [Figs. 2 and 3].

The shape of the lesion was regular and without a cleavage plane separating it from the adjacent muscle layers. Densitometric values indicated adipose tissue in $75 \%$ of the lesion whereas the distal third portion of the lesion appeared fibrous with no enhancement after administration of contrast medium. These findings suggested a lipomatous mass as already suspected at US. The lesion underwent surgical excision, and histological examination of the

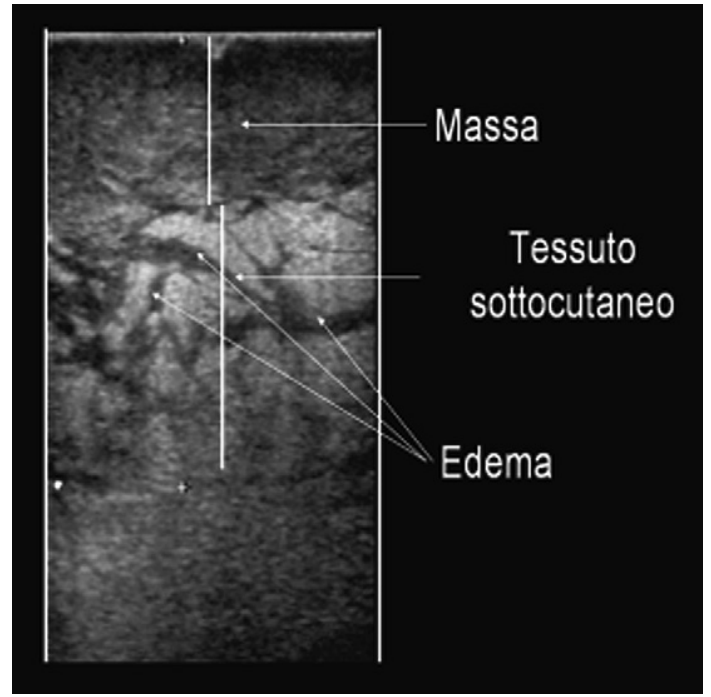

Figure 1 US image using a high-frequency probe shows a mass of inhomogeneous echotexture and deep, poorly delineated margins; there is thickening of the subcutaneous tissue due to marked edema.

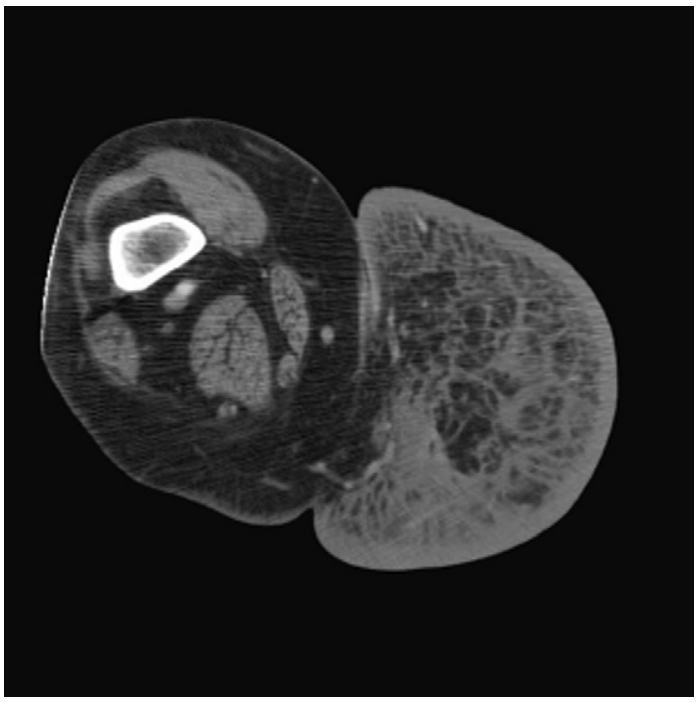

Figure 2 CT scan and 3D reconstruction show a large oval mass with regular margins and fibrous tissue involving the skin; the lesion extends from the scrotum to the distal third of the femur. The mass presents inhomogeneous density and is poorly vascularized.

specimen confirmed diagnosis. Informed consent was obtained from the patient for the publication of this case report and accompanying images.

\section{Discussion}

Lipomas are frequent benign soft tissue tumors classified as superficial or deep. Clinically, lipomas appear as well delineated asymptomatic lesions [2] and in some cases they can reach a considerable size [4].

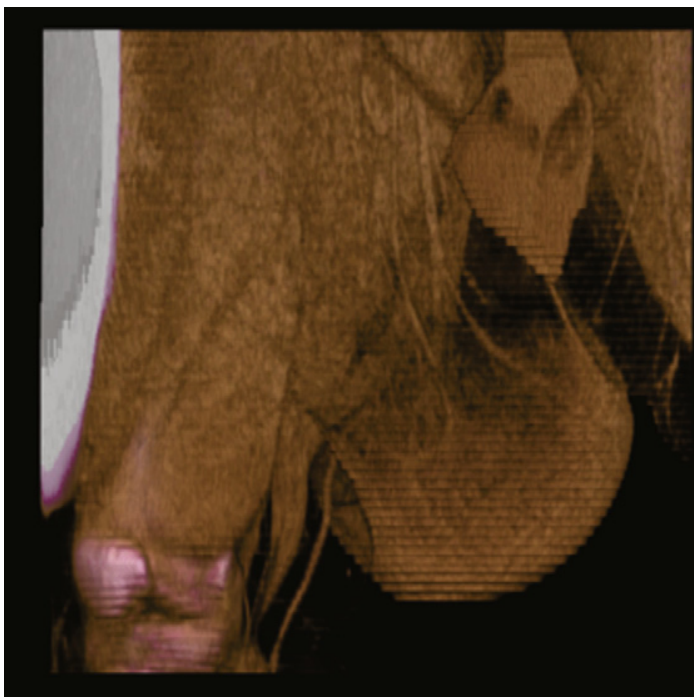

Figure 3 CT scan and 3D reconstruction show a large oval mass with regular margins and fibrous tissue involving the skin; the lesion extends from the scrotum to the distal third of the femur. The mass presents inhomogeneous density and is poorly vascularized. 
Gray-scale US integrated with color Doppler, power Doppler and spectral curve analysis are easily available, noninvasive and inexpensive tools which do not involve ionizing radiation. US is the diagnostic imaging method of choice in the initial assessment of soft tissue lesions whose origin and nature are not fully understood, for a possible US-guided needle biopsy [5] and for comparison with the outcome of contrast enhanced CT.

In the present case, US revealed a large mass which was ill-definable due to the large size, and only in the peripheral portion it seemed to be delimited by the adjacent muscle layers. Malignant lesions such as high grade liposarcomas show no plane of cleavage between the mass and adjacent muscle layers and they present infiltrative growth and tumor digitations $[7,8]$. In the present case, US did not permit exact definition of the lesion which presented peripheral fibrosis and digitations which reached the skin and deeper subcutaneous layers. US furthermore showed diffuse reactive skin thickening which increased the skin thickness (epidermis and dermis) by about $18 \mathrm{~mm}$ due to the presence of abundant edema as compared to 2-3 $\mathrm{mm}$ thickness in physiological conditions. Integration with Color Doppler showed complete absence of signal.

Benign tumors of adipose origin are typically characterized by a homogeneous echostructure, regular contours, small dimensions (less than $5 \mathrm{~cm}$ in diameter), a fat content greater than $75 \%$, no infiltrating margins and absent or peripheral vascularity. High grade liposarcomas are characterized by inhomogeneous echotexture, the presence of nodular or globular non-adipose areas and a fat content of less than 75\%; they are typically large with irregular or poorly defined infiltrating contours as well as anarchic peripheral and intralesional vascularization.

The present lesion presented several characteristics indicating malignancy such as the large size, inhomogeneous echostructure and poorly-defined margins, but at the same time some benign characteristics such as a fat content greater than $75 \%$, the absence of vascularization and mainly regular contours.

Despite the difficulty in differentiating between a benign lesion and a lesion of low-grade malignancy, combination of US and contrast enhanced CT allowed a tentative diagnosis of giant lipoma of the thigh which was confirmed by subsequent histological examination of the surgical specimen.

\section{Conflict of interests}

The authors have no conflicts of interest to disclose.

\section{Appendix. Supplementary data}

Supplementary data related to this article can be found online at doi:10.1016/j.jus.2012.02.010.

\section{References}

[1] Danzi M, Grimaldi L, Reggio S, Danzi R. Giant atypical lipoma of the thigh. Case report and literature review. G Chir 2010 Mar; 31(3):108-11.

[2] Alaggio R, Coffin CM, Weiss SW, Brdge JA, Issakov J, Oliveira AM, et al. Liposarcomas in young patients: a study of 82 cases occurring in patients younger than 22 years of age. Am J Surg Pathol 2009 May;33(5):645-58.

[3] Grivas TB, Psarakis SA, Kaspiris A, Liapi G. Giant lipoma of the thenar-case study and contemporary approach to its aetiopathogenicity. Hand (N Y) 2009 Jun;4(2):173-6. Epub 2008 Dec 18.

[4] Whittle C, Cortés M, Baldassare G, Castro A, Cabrera R. Subgaleal lipomas: ultrasound findings. Rev Med Chil 2008 Mar; 136(3):334-7.

[5] Widmann G, Riedl A, Schoepf D, Glodny B, Peer S, Gruber H. State-of-the-art HR-US imaging findings of the most frequent musculoskeletal soft-tissue tumors. Skeletal Radiol 2009 Jul; 38(7):637-49. Epub 2008 Oct 10. Review.

[6] Kransdorf MJ, Bancroft LW, Peterson JJ, Murphey MD, Foster WC, Temple HT. Imaging of fatty tumors: distinction of lipoma and well-differentiated liposarcoma. Radiology 2002; Jul;224(1):99-104.

[7] Dei Tos AP. Liposarcoma: new entities and evolving concepts. Ann Diagn Pathol 2000 Aug;4(4):252-66. Review.

[8] Weiss SW. Lipomatous tumors. Monogr Pathol 1996;38:207-39. Review. 